\title{
The Influence of Sexual Objectification Experience on Chinese Female College Students' Selfie-Posting Behavior: A Mediated Moderation Model
}

\author{
Mingming Huang1, Shouying Zhao², Qiannan Ma3, Wenhao Pan² \\ ${ }^{1}$ Inner Mongolia Normal University, Hohhot, China \\ ${ }^{2}$ Guizhou Normal University, Guiyang, China \\ ${ }^{3}$ Zhoukou Normal University, Zhoukou, China \\ Email: *zhaoshouying@126.com
}

How to cite this paper: Huang, M. M., Zhao, S. Y., Ma, Q. N., \& Pan, W. H. (2019). The Influence of Sexual Objectification Experience on Chinese Female College Students' Selfie-Posting Behavior: A Mediated Moderation Model. Psychology, 10, 2080-2090.

https://doi.org/10.4236/psych.2019.1015134

Received: November 2, 2019

Accepted: December 23, 2019

Published: December 26, 2019

Copyright $\odot 2019$ by author(s) and Scientific Research Publishing Inc. This work is licensed under the Creative Commons Attribution International License (CC BY 4.0).

http://creativecommons.org/licenses/by/4.0/

\begin{abstract}
Sexual objectification experience is that person experienced life with objectified information. In order to explore the influence of the sexual objectification experience on female college students' selfie-posting behavior, $700 \mathrm{fe}$ male college students were surveyed with the Interpersonal Sexual Objectification scale, Enjoyment of Sexualization scale, Social Network Selfile-posting scale and Imaginary Audience Ideation scale. The results show that: 1) Sexual objectification experience is significantly correlated with female college students' selfie-posting behavior and enjoyment of sexualization. Female college students' enjoyment of sexualization is significantly correlated with selfie-posting behavior. 2) Sexual objectification experience can predict female college students' selfie-posting behavior through the partial mediating role of enjoyment of sexualization, and the mediating role of enjoyment of sexualization is moderated by female college students' imaginary audience ideation. This research revealed the mechanism of the relationship between sexual objectification experience and selfie-posting behavior, which helps to guide female college students to actively and healthfully participate in social activities.
\end{abstract}

\section{Keywords}

Sexual Objectification Experience, Selfie-Posting Behavior, Enjoyment of Sexualization, Imaginary Audience Ideation, Chinese College Students

\section{Introduction}

Selfie-posting behavior (SPB) is a kind of sharing behavior in which individuals 
use their mobile phones or cameras to upload photos to social networking sites (Sorokowski, Sorokowska, Oleszkiewicz et al., 2015); it is a new way of self-disclosure in social networks. Studies have shown that excessively posting photos with objectification information is likely to lead to female students' self-objectification (Cohen, Newton-John, \& Slater, 2018; Luo, Niu, Kong et al., 2019), which will make them ignore their own traits of personality and have serious effects on their physical and mental health. Female college students are a special group; the frequency of their selfie-posting behavior is very high. There are many factors that can cause female college students to post their selfies on social networking sites. Exploring the impact of these factors on selfie-posting behavior is of great significance to reduce the negative effects of selfie-posting behavior on Female college students' physical and mental health.

Sexual Objectification Experience (SOE) is that person experienced life with objectified information, and Interpersonal Sexual Objectification (ISO) refers to the sexual objectification experience in actual interpersonal relationships and social interactions, such as looking at women or giving sexual comments on women (Fredrickson \& Roberts, 1997). For women, interpersonal objectification exists everywhere; women experience an average of 1.38 sexual objectifications and behaviors every week (Swim, Hyers, Cohen, \& Ferguson, 2001). Women with these sexual objectification experience often mistakenly believe that they have a good appearance to attract men. Previous studies found that sexual objectification experience can tend to get high level of self-objectification (Li, Yin, \& Shen, 2015). Mabe \& Forney et al. (2014) found that selfie-posting behaviors play a mediating role in young women's self-objectification and eating disorders (Mabe, Forney, \& Keel, 2014); it can be seen that self-objectification can significantly predict individual selfie-posting behavior. Yang Xiujuan, Zhou Zongkui, Liu Qingqi et al. (2017) found that college students' self-posting is influenced by self-objectification when it affects women's selfie-posting behavior. When the level of self-objectification is high, college female students' selfie-posting behavior tends to be obvious, thus indicating that self-objectification can promote the level of college students' self-posting (Yang, Zhou, Liu et al., 2017). The objectification theory points out that sexual objectification experiences make women look at themselves as observers (Fredrickson \& Roberts, 1997), which will lead women to show a high degree of attention to their physical appearance, and tend to upload more photos to social networking sites (Aubrey, 2006). Therefore, this study assumes that $\mathrm{H} 1$ : Sexual objectification experience can predict female college students' selfie-posting behavior.

The study about the influence mechanism of sexual objectification experience on female college students' selfie-posting behavior can be carried out from the perspective of female college students' attitude to sexual objectification experience. Enjoyment of Sexualization (ESL) refers to the subjective feelings that women like to get "sexual attention" from men, or the experience of women seeking and enjoying to be treated as "sexual objects" (Liss et al., 2010). In some cultures or fields, there are also some forms of sexual objectification recognized 
and encouraged by society, such as dance performances, etc. (Gill, 2008), people often regard it as a kind of beauty and go to enjoy it. When women benefit from being "sexualized", they tend to enjoy the sexual objectification experience, and upload their own photos to social networking sites. In daily life, men usually look back to them, which make female college students often think that they have high enough charm and attractiveness. In addition to this, previous studies found that Enjoyment of Sexualization can significantly predict the level of self-objectification and their self-posting release behavior (Mabe, Forney, \& Keel, 2014). Therefore, this study assumes that H2: Enjoyment of Sexualization plays a mediating role between sexual objectification experience and female students' selfie-posting behavior.

We are also worth paying attention to the individual differences in the mediating role of Enjoyment of Sexualization between sexual objectification experience and selfie-posting behavior. Imaginary audience ideation (IMAI) refers to the fact that an individual has a belief that others have been paying attention to himself or herself (Martin \& Sokol, 2011). Women with obvious feminist tendencies have higher acceptance of sexual objectification experience and are more interested in "sexualized" feelings (Erchull \& Liss, 2013), they are eager to get others' attention, then the level of Enjoyment of Sexualization will be higher. Women with high levels of Imaginary audience ideation are more sensitive to interpersonal objectification experiences, which may awake women's attention to their own self-physical appearance, then their sexual self-objectification can be formed easily (Zheng, Ni, \& Luo, 2018). The objectification theory also points out that the sexual objectification experience will make individuals have more social comparisons with other women, when comparing the downward society, their self-assessment will be higher (Fredrickson \& Roberts, 1997). Women with high level of Imaginary audience ideation will feel more enjoyable and will be more likely to post selfies on social networking sites. Therefore, this study assumes that H3: Imaginary audience ideation may moderate the mediating role of Enjoyment of Sexualization between sexual objectification experience and female students' selfie-posting behavior.

In summary, this study intends to explore the influence of sexual objectification experience on female college students' selfie-posting behavior, and analysis mediating role of Enjoyment of Sexualization and the moderating role of Imaginary audience ideation (Figure 1).

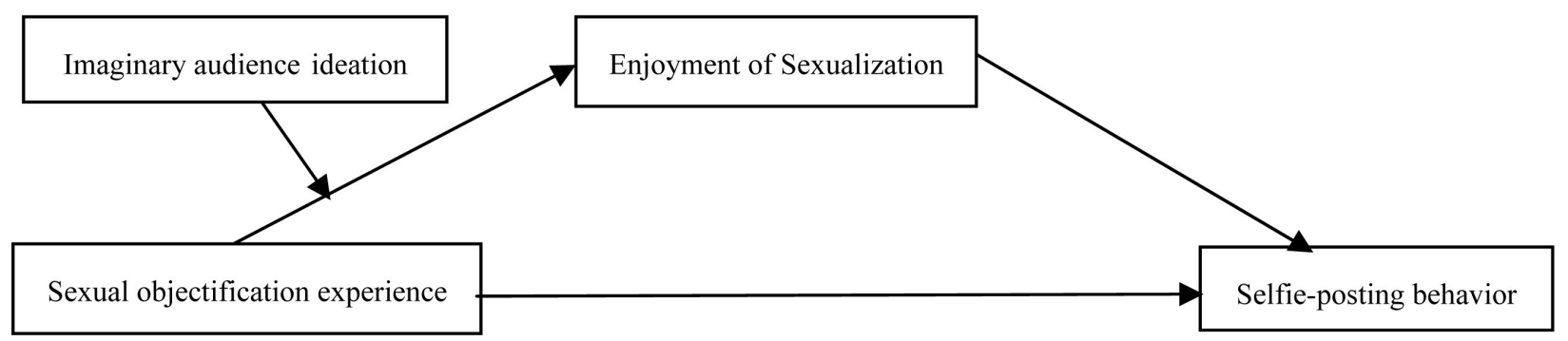

Figure 1. Hypothesis framework of this study. 


\section{Methods}

\subsection{Participants}

Participants were randomly selected from 2 universities from Jiangxi province in China. 700 questionnaires were received and the valid sample included $668 \mathrm{fe-}$ male college students. Participants' age ranged from 18 to 25 years old with a mean age of $20.57(\mathrm{SD}=1.07)$.

\subsection{Measures}

\subsubsection{Interpersonal Sexual Objectification Scale}

The Interpersonal Sexual Objectification Scale (ISOS) was developed by Kozee, Tylka, Augustus-Horvath and Denchik (Kozee, Tylka, Augustus-Horvath et al., 2007). The scale has 15 items, which are all rated on 5-point Likert scale ( $1=$ never, 5 = almost always). This scale includes two dimensions of physical assessment and sexual harassment, and it is used to measure the individual's Sexual Objectification experience in interpersonal relationships in the past one year. This scale is mainly used for women. When the total score of this scale is high, women had more Sexual Objectification experience. Studies have shown that this scale has good reliability and validity in the female population (Meghan, Gervais, Canivez et al., 2013). In this study, the Cronbach $\alpha$ coefficient of the scale is 0.825 . The fit index of confirmatory factor analysis is good $\left(\chi^{2} / \mathrm{df}=3.478\right.$; $\mathrm{GFI}=0.951 ; \mathrm{TFI}=0.911 ; \mathrm{CFI}=0.973 ; \mathrm{RMSEA}=0.074)$.

\subsubsection{Enjoyment of Sexualization Scale}

The enjoyment of sexualization scale (ESS) was developed by Liss et al. (Liss, Erchull, \& Ramsey, 2010), and then was translated into Chinese by Hou Fuyuan (Hou, 2018). The scale has 8 items for measuring individual level of Enjoyment of Sexualization, and it is mainly used to measure the degree that women enjoy the sexual attention from men. All the items are all rated on 5-point Likert scale ( $1=$ very disagree, $6=$ very agree). In this study, the Cronbach $\alpha$ coefficient of the scale is 0.809 . The fit index of confirmatory factor analysis is good $\left(\chi^{2} / \mathrm{df}=\right.$ 3.478; $\mathrm{GFI}=0.951$;FI $=0.911$; CFI $=0.973$; $\mathrm{RMSEA}=0.074)$.

\subsubsection{Social Network Selfile-Posting Scale}

The selfie posting behavior questionnaire was develpoed to measure the frequency of individuals post selfie on social networking sites by Fardouly J and Vartanian L R (Fardouly \& Vartanian, 2015). Selfie-posting frequency was measured using one item, "How often would you say that you take and post selfies on SNSs?", a total of 0 - 8 The frequency ranges from "less than once a year" to "a few times a day". In this study, we asked two Masters of English major and one doctor of Psychology major to translate this scale into Chinese version.

\subsubsection{Imaginary Audience Ideation Scale}

The imaginary audience ideation scale was developed by Liu Jianrong and Li lin (Liu \& Li, 2010), which is designed to assess one's imaginary audience ideation. The IAIS has 6 items, which are all rated on 5 -point Likert scale $(1=$ strongly 
disagree, 5 = completely agree). When the total score is higher, the level of imaginary audience ideation will become higher. Previous study has shown that this scale has good reliability and validity among college students (Yang, Song, \& Lian, 2018). In this study, the Cronbach $\alpha$ coefficient of the scale was 0.764 . The fit index of confirmatory factor analysis is good $\left(\chi^{2} / \mathrm{df}=4.517\right.$; GFI $=0.951$; TFI $=0.911 ; \mathrm{CFI}=0.973 ; \mathrm{RMSEA}=0.076)$.

\subsection{Data Analysis}

In this study, SPSS21.0 was used to conduct descriptive analysis, correlation analysis and common method variance analysis. AMOS21.0 was used for confirmatory factor analysis, and bias-corrected Bootstrap method was used to analysis the mediating effect of enjoyment of sexualization and the moderating effect of imaginary audience ideation.

\section{Results}

\subsection{Common Method Variance Analysis}

In this study, Harman single-factor method was used to analyze the data. The results show that there were 9 common factors being extracted and the first common factor explained $28.3 \%$ of the total variance, it was far less than $40 \%$ (Podsakoff, MacKenzie, Lee et al., 2003), so, this current study doesn't exist obvious common method variance.

\subsection{Description and Correlation Statistics}

Descriptive statistics and correlation analysis were performed on each variable in the study (Table 1). The correlation analysis between variables shows that there is a significant positive correlation between Sexual objectification experience and the Enjoyment of Sexualization among female college students, and there is a significant positive correlation with the selfie-posting behavior. There is also a significant positive correlation between the Enjoyment of Sexualization and selfie-posting behavior.

\subsection{The Moderated Mediation Model}

Firstly, the total effect of sexual objectification experience on female college students' selfile-posting behavior is examined. It is found that the total effect of

Table 1. Descriptive analysis and correlation matrix of each variable in the study $(\mathrm{n}=$ 688).

\begin{tabular}{|c|c|c|c|c|}
\hline variables & $\bar{x} \pm \mathrm{s}$ & 1 & 2 & 3 \\
\hline 1. sexual objectification experience & $1.63 \pm 0.51$ & 1 & & \\
\hline 2. enjoyment of sexualization & $2.68 \pm 0.62$ & $0.333^{* *}$ & 1 & \\
\hline 3. selfie-posting behavior & $3.00 \pm 1.51$ & $0.233^{\star *}$ & $0.209^{\star *}$ & 1 \\
\hline
\end{tabular}


sexual objectification experience on female college students' selfie-posting behavior is significant $(\beta=0.25, t=3.99, p<0.001)$, and the $95 \%$ confidence interval is [0.12 0.37]. Next, we examine the moderating mediation model.

Bias-Corrected Percentile Bootstrap Method derived from 2000 bootstrap re-samples was estimated to test for the significance of conditional direct and indirect effects. The results showed that the moderated mediating model fits well $\left(\chi^{2} / \mathrm{df}=2.73, \mathrm{CFI}=0.99, \mathrm{TLI}=0.93, \mathrm{RMSEA}=0.049\right)$, as is shown below (Figure 2 ). The sexual objectification experience can positively predict female students' enjoyment of sexualization $(\beta=0.25, t=4.06, p<0.001)$, and also can positively predict female college students' selfie-posting behavior $(\beta=0.19, t=$ $3.02, p=0.003<0.05)$; the level of Enjoyment of Sexualization can positively predict female college students' selfie-posting behavior $(\beta=0.14, t=2.41, p=$ $0.016<0.05)$. So, Enjoyment of Sexualization plays a partial mediating role between the sexual objectification experience and the selfie-posting behavior.

In addition to this, the interaction between sexual objectification experience and Imaginary audience ideation can positively predict the level of female college students' Enjoyment of Sexualization $(\beta=0.14, t=2.42, p=0.016<0.05)$, which indicates that the mediating role of enjoyment of sexualization is moderated by the level of Imaginary audience ideation.

In order to clearly reveal the moderating effect of the Imaginary audience ideation, this study divided participants into two groups by the level of imaginary audience ideation: high group $(M+1 S D)$ and low group (M 1SD) based on one standard deviation, and then the simple slope test is performed. The result shows that: the prediction effect of sexual objectification experience on Enjoyment of Sexualization has a significant effect in high group $(\beta=0.423, t=3.083, p<$ $0.05)$, but the prediction effect is not significant in the low group $(\beta=-0.040, t=$ $-1.263, p=0.205>0.05)$, as shown in Figure 3. The results show that: The Bootstrap 95\% confidence interval of the mediating effect does not contain 0 at different levels of the Imaginary audience ideation, and the mediating effect rises $(0.019,0.081,0.134)$ with the increasing level of the Imaginary audience ideation, which indicates that the mediating role of Enjoyment of Sexualization in

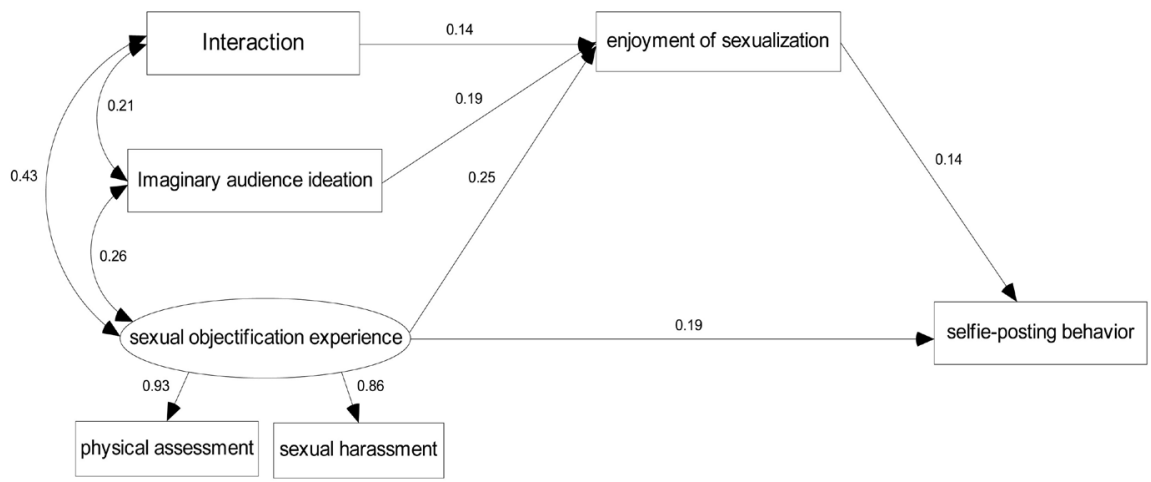

Figure 2. The influence of sexual objectification experience on selfie-posting behavior (standardization). 


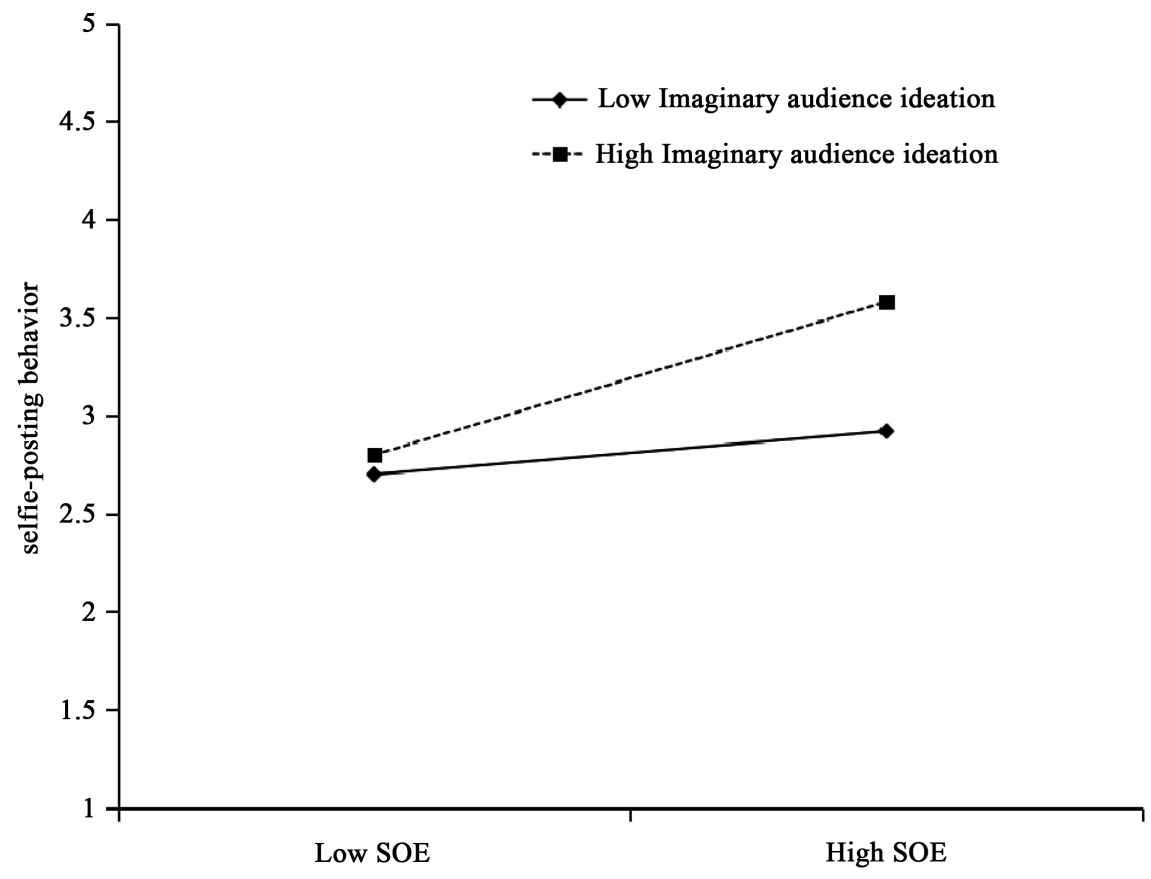

Figure 3. Simple slope test of the Imaginary audience ideation.

between sexual objectification experience and selfie-posting behavior will be moderated by the level of female college students' Imaginary audience ideation, that's to say, with the increasing of female college students' imaginary audience ideation, the mediating effect of Enjoyment of Sexualization will be promoted.

\section{Discussion}

This study found that the sexual objectification experience can significantly predict female college students' selfie-posting behavior, which is consistent with the previous studies (Mabe, Forney, \& Keel, 2014), this result indicates that sexual objectification experience can significantly influence individual's selfie-posting behavior, thus verified the hypothesis $\mathrm{H} 1$ of this study. Female college students with more sexual objectification experience would like to pay more attention to their own body image, when they are stared by men or sexually commented, they tend to think that they have an attractive body image, and then glad to post their own photos on social networking sites to show their charming body image (Cohen, Newton-John, \& Slater, 2018). So, sexual objectification experience is one of the important factors to predict female students' selfie-posting behavior.

Mediation analysis showed that Enjoyment of Sexualization plays a partial mediating role between sexual objectification experience and selfie-posting behavior, which verified hypothesis $\mathrm{H} 2$ and is consistent with the previous research (Barnett, Maciel, \& Gerner, 2018; Visser, Sultani, Choma et al., 2014). Impression management theory points out that individuals tend to adopt strategies to control others' impressions on themselves to achieve a good impression (Liu, 2006), such as presenting or publishing information that is beneficial to their body image. Ridgway \& Clayton (2016) found that when individuals are sa- 
tisfied with their body image, they tend to show their own good image, which is conducive to improving themselves (Ridgway \& Clayton., 2016). After experiencing sexual objectification, women usually mistakenly think that they have attractive body image, and then post their own photos on social networking sites. Secondly, female college students' Enjoyment of Sexualization also plays a mediating role. When female college students' body image can cause others' attention, then they will enjoy it and have feeling of being sexualized (Langlois et al., 2000). Some studies have pointed out that Enjoyment of Sexualization will bring a series of serious social consequences (Pellizzer et al., 2016), the reason for this difference may be that women have different attitudes on being sexualized. Studies show that the charm of their own appearance is also the standard that men give them some evaluation on their body image, and women who meet these social ideal standards will get a greater reciprocation (Fiske, Bersoff, Borgida et al., 1991), so, female students often choose to post their own photos on social networking sites. Therefore, we can reduce the frequency of objectifying selfie-posting behavior by making an intervention on female college students' Enjoyment of Sexualization.

In addition to this, the influence of sexual objectification experience on female college students' selfie-posting behavior will be moderated by the level of Imaginary audience ideation, that's to say, compared with the female college students with lower level of Imaginary audience ideation, female college students with high level of Imaginary audience ideation have a more significant prediction on selfie-posting behavior, which verified the hypothesis $\mathrm{H} 3$ and is consistent with the previous research (Zheng, Ni, \& Luo, 2018), this result illustrated that individual differences in the mediating role between Enjoyment of Sexualization and selfie-posting behavior. Goossens, L. (1984) pointed out that people with high-level Imaginary audience ideation is very concerned about others' perceptions of themselves (Goossens, 1984). When experiencing sexual objectification, women are confusing "attractiveness" with "being sexualized", then they will enjoy with their own physical appearance.

This study applies the moderating role of Imaginary audience ideation to the mediating role of Enjoyment of Sexualization and reveals that Imaginary audience ideation can promote mediating effect of Enjoyment of Sexualization, which enriched our recognition about the factors of the selfie-posting behavior. At the same time, the mediating role of Enjoyment of Sexualization can be moderated by level of female college students' Imaginary audience ideation.

\section{Conclusion}

1) Sexual objectification experience has a significant effect on female college students' selfie-posting behavior.

2) Sexual objectification experience can influence female college students' selfie-posting behavior through Enjoyment of Sexualization.

3) Imaginary audience ideation can moderate the mediating role of Enjoyment of Sexualization. 


\section{Funding}

General Project of Post-funded Project of Philosophy and Social Science Research of Ministry of Education (Project Number: 14JHQ016); General Project of Science and Technology Fund of Guizhou Province (Project Number: 15XJC880007).

\section{Conflicts of Interest}

The authors declare no conflicts of interest regarding the publication of this paper.

\section{References}

Aubrey, J. S. (2006). Effects of Sexually Objectifying Media on Self-Objectification and Body Surveillance in Undergraduates: Results of a 2-Year Panel Study. Journal of Communication, 56, 21-28. https://doi.org/10.1111/j.1460-2466.2006.00024.x

Barnett, M., Maciel, I., \& Gerner, M. (2018). Enjoyment of Sexualization and Feminism: Relationships with Sexual Self-Schema and Psychosexual Health. Sexuality \& Culture, 22, 669-684. https://doi.org/10.1007/s12119-018-9515-5

Cohen, R., Newton-John, T., \& Slater, A. (2018). Selfie-Objectification: The Role of Selfies in Self-Objectification and Disordered Eating in Young Women. Computers in Human Behavior, 79, 68-74. https://doi.org/10.1016/j.chb.2017.10.027

Erchull, M. J., \& Liss, M. (2013). Feminists Who Flaunt It: Exploring the Enjoyment of Sexualization among Young Feminist Women. Journal of Applied Social Psychology, 43, 2341-2349. https://doi.org/10.1111/jasp.12183

Fardouly, J., \& Vartanian, L. R. (2015). Negative Comparisons about One's Appearance Mediate the Relationship between Facebook Usage and Body Image Concerns. Body Image, 12, 82-88. https://doi.org/10.1016/j.bodyim.2014.10.004

Fiske, S. T., Bersoff, D. N., Borgida, E. et al. (1991). Social Science Research on Trial: Use of Sex Stereotyping Research in Price Waterhouse v. Hopkins. American Psychologist, 46, 1049-1060. https://doi.org/10.1037/0003-066X.46.10.1049

Fredrickson, B. L., \& Roberts, T. (1997). Objectification Theory: Toward Understanding Women's Lived Experiences and Mental Health Risks. Psychology of Women Quarterly, 21, 173-206. https://doi.org/10.1111/j.1471-6402.1997.tb00108.x

Gill, R. (2008). Empowerment/Sexism: Figuring Female Sexual Agency in Contemporary Advertising. Feminism \& Psychology, 18, 35-60. https://doi.org/10.1177/0959353507084950

Goossens, L. (1984). Imaginary Audience Behavior as a Function of Age, Sex and Formal Operational Thinking. International Journal of Behavioral Development, 7, 77-93. https://doi.org/10.1177/016502548400700106

Hou, F. Y. (2018). The Effect of Media Information on College Female Students' Self-Objectification: The Mediating Role of Enjoyment of Sexualization. Master Thesis, Changchun: Jilin University.

Kozee, H. B., Tylka, T. L., Augustus-Horvath, C. L. et al. (2007). Development and Psychometric Evaluation of the Interpersonal Sexual Objectification Scale. Psychology of Women Quarterly, 31, 176-189. https://doi.org/10.1111/j.1471-6402.2007.00351.x

Langlois, J. H., Kalakanis, L., Rubenstein, A. J. et al. (2000). Maxims or Myths of Beauty? A Meta-Analytic and Theoretical Review. Psychological Bulletin, 126, 390-423. https://doi.org/10.1037/0033-2909.126.3.390 
Li, J.-Y., Yin, Q., \& Shen, X.-X. (2015). Effect of Sexual Objectification on Women's Self-Objectification: Moderated Mediating Effect. Chinese Journal of Clinical Psychology, 23, 1089-1093.

Liss, M., Erchull, M. J., \& Ramsey, L. R. (2010). Empowering or Oppressing? Development and Exploration of the Enjoyment of Sexualization Scale. Personality and Social Psychology Bulletin, 37, 55-68. https://doi.org/10.1177/0146167210386119

Liu, J. J. (2006). Commentary on Impression Management and Its Relative Research. Advances in Psychological Science, 14, 309-314.

Liu, J. R., \& Li, L. (2007). Preliminary Investigation on the Self-Centered Status of 93 High School Students in a School in Fuzhou City. Chinese Mental Health Journal, 21, 461-463.

Luo, Y.-J., Niu, G.-F., Kong, F.-C. et al. (2019). Online Interpersonal Sexual Objectification Experiences and Chinese Adolescent Girls' Intuitive Eating: The Role of Broad Conceptualization of Beauty and Body Appreciation. Eating Behaviors, 4, 55-60. https://doi.org/10.1016/j.eatbeh.2019.03.004

Mabe, A. G., Forney, K. J., \& Keel, P. K. (2014). Do You "Like” My Photo? Facebook Use Maintains Eating Disorder Risk. International Journal of Eating Disorders, 47, 516-523. https://doi.org/10.1002/eat.22254

Martin, J., \& Sokol, B. (2011). Generalized Others and Imaginary Audiences: A Neo-Meadian Approach to Adolescent Egocentrism. New Ideas in Psychology, 29, 364-375. https://doi.org/10.1016/j.newideapsych.2010.03.006

Meghan, D. M., Gervais, S. J., Canivez, G. L. et al. (2013). A Psychometric Examination of the Interpersonal Sexual Objectification Scale among College Men. Journal of Counseling Psychology, 60, 239-250. https://doi.org/10.1037/a0032075

Pellizzer, M., Tiggemann, M., \& Clark, L. (2016). Enjoyment of Sexualisation and Positive Body Image in Recreational Pole Dancers and University Students. Sex Roles, 74, 35-45. https://doi.org/10.1007/s11199-015-0562-1

Podsakoff, P. M., MacKenzie, S. B., Lee, J. Y. et al. (2003). Common Method Biases in Behavioral Research: A Critical Review of the Literature and Recommended Remedies. Journal of Applied Psychology, 88, 879-880. https://doi.org/10.1037/0021-9010.88.5.879

Ridgway, J. L., \& Clayton, R. B. (2016). Instagram Unfiltered: Exploring Associations of Body Image Satisfaction, Instagram Selfie Posting, and Negative Romantic Relationship Outcomes. Cyberpsychology Behavior and Social Networking, 19, 2-7.

https://doi.org/10.1089/cyber.2015.0433

Sorokowski, P., Sorokowska, A., Oleszkiewicz, A. et al. (2015). Selfie-Posting Behaviors Are Associated with Narcissism among Men. Personality \& Individual Differences, 85, 123-127. https://doi.org/10.1016/j.paid.2015.05.004

Swim, J. K., Hyers, L. L., Cohen, L. L., \& Ferguson, M. J. (2001). Everyday Sexism: Evidence for Its Incidence, Nature, and Psychological Impact from Three Daily Diary Studies. Journal of Social Issues, 57, 31-53. https://doi.org/10.1111/0022-4537.00200

Visser, B. A., Sultani, F., Choma, B. L. et al. (2014). Enjoyment of Sexualization: Is It Different for Men? Journal of Applied Social Psychology, 44, 495-504. https://doi.org/10.1111/jasp.12241

Yang, P.-F., Song, Y.-H., \& Lian, S.-L. (2018). Effect of Imaginary Audience on Sense of Alienation in Adolescents: The Mediating Role of Social Anxiety. Chinese Journal of Clinical Psychology, 26, 74-77.

Yang, X. J., Zhou, Z. K., Liu, Q. Q. et al. (2017). Narcissism and Social Networking Sites Use. Advances in Psychological Science, 25, 1552-1564. 
Zheng, D., Ni, X.-L., \& Luo, Y.-J. (2018). Selfie Posting on Social Networking Sites and Female Adolescents' Self-Objectification: The Moderating Role of Imaginary Audience Ideation. Sex Roles, 80, 325-331. https://doi.org/10.1007/s11199-018-0937-1 